\title{
PELATIHAN KETERAMPILAN MENELITI UNTUK CALON GURU BIOLOGI
}

\author{
Ipin Aripin ${ }^{1,2}$, Topik Hidayat ${ }^{3}$, Nuryani Rustaman ${ }^{3,4}$, Riandi ${ }^{3,4}$, \\ Vitta Yaumul Hikmawati ${ }^{2}$, Dadang Sudirno ${ }^{5}$, Dede Salim Nahdi ${ }^{5}$, Dindin Nasrudin ${ }^{6}$
}

\author{
${ }^{1}$ Program Studi Pendidikan Biologi, Universitas Majalengka \\ ${ }^{2}$ Program Studi Pendidikan IPA, Sekolah Pascasarjana Universitas Pendidikan Indonesia \\ ${ }^{3}$ Departemen Pendidikan Biologi, Universitas Pendidikan Indonesia \\ ${ }^{4}$ Sekolah Pascasarjana, Universitas Pendidikan Indonesia \\ ${ }^{5} \mathrm{P} 3 \mathrm{M}$ Universitas Majalengka \\ ${ }^{6}$ Universitas Islam Negeri Sunan Gunung Djati Bandung \\ *ipin_aripin@unma.ac.id
}

\begin{abstract}
The purpose of this community service (CS) is to improve the research skills of prospective biology teachers, especially Biology Education students on campuses located in Region III of Cirebon. The method used in this CS is a research skills training workshop which consists of theoretical and practical training so that there is a transfer of knowledge to activity participants. The methods to improve research skills in prospective biology teachers are carried out through the provision of theoretical knowledge, the practice of preparing research proposals and the preparation of scientific articles as well as ways of publishing research results. The results of the analysis of participants' responses to this CS activity concluded that participants stated that this activity was very useful in providing basic research skills. The results of the analysis of the assignments given indicate that the tasks carried out by the participants are quite good, meaning that they still require further debriefing related to theory and especially the practice of research activities on participants. There is a need for continuous workshop activities by focusing on best practice in research activities in the field of education and research in the field of pure science.
\end{abstract}

Keywords: research skills, prospective biology teacher's

\begin{abstract}
Abstrak
Tujuan PKM ini adalah untuk meningkatkan keterampilan meneliti pada calon guru biologi khususnya pada mahasiswa Pendidikan Biologi di kampus yang berada di wilayah III Cirebon. Metode yang digunakan pada PKM ini adalah workshop pembekalan keterampilan meneliti yang terdiri dari pembekalan teoritis dan praktis sehingga terjadi transfer of knowledge kepada peserta kegiatan. Metode untuk meningkatkan keterampilan meneliti pada calon guru biologi dilakukan melalui pembekalan pengetahuan teoritis, praktik penyusunan proposal penelitian dan penyusunan artikel ilmiah serta cara publikasi hasil penelitian. Hasil analisis terhadap respon peserta pada kegiatan PKM ini menyimpulkan bahwa peserta menyatakan bahwa kegiatan ini sangat bermanfaat dalam memberikan bekal dasar keterampilan meneliti. Hasil analisis terhadap penugasan yang diberikan menunjukkan bahwa tugas yang dikerjakan peserta tergolong cukup baik, artinya masih memerlukan pembekalan lebih lanjut terkait dengan teori dan khususnya praktik kegiatan meneliti pada peserta. Perlu adanya kegiatan workshop yang berkelanjutan dengan memfokuskan pada best practice dalam kegiatan riset dalam bidang pendidikan maupuan riset pada bidang sains murni.
\end{abstract}

Kata kunci: Keterampilan meneliti, calon guru biologi

\begin{tabular}{l|l|l} 
Submitted: 2021-07-09 & Revised: 2021-07-29 & Accepted: 2021-07-31
\end{tabular}

\section{Pendahuluan}

Keterampilan meneliti merupakan keterampilan yang dibutukan dalam melakukan penelitian termasuk penggunaan alat, strategi, keterampilan pemecahan masalah, berpikir kritis, dan diseminasi hasil penelitian (Meerah \& Arsad, 2010). Hal ini sejalan dengan kerangka kerja keterampilan Abad-21 yang mensyaratkan penguasaan keterampilan pemecahan masalah, berpikir kritis, berkomunikasi, dan penggunaan ICT (Voogt \& Roblin, 2012). Saat ini penelitian sudah dianggap bagian penting dari pendidikan khususnya pendidikan sains pada tingkatan sekolah dan perguruan tinggi (Kapon, 2016). Keterampilan meneliti dalam bidang sains khususnya mengacu 
pada kemampuan untuk menerapkan pengetahuan prosedural dan deklaratif untuk membuat dan melakukan percobaan ilmiah dengan benar (Gott, 1987). Keterampilan penelitian merupakan keterampilan esensial dalam dunia kerja karena dengan menguasai RS, sebuah perusahaan dapat terus melakukan riset dan pengembangan usahanya (Bandaranaike, 2018). Riset dan inovasi merupakan bagian penting dalam pengembangan ilmu pengetahuan dan teknologi, pondasi untuk pengembangan riset dan teknologi adalah membekalkan keterampilan riset yang berkualitas pada calon-calon peneliti di masa mendatang, tugas tersebut dapat dilakukan oleh perguruan tinggi sebagai intitusi pendidikan yang juga berperan sebagai pusat pengembangan ilmu pengetahuan dan teknologi.

Masih rendahnya keterampilan meneliti di Indonesia baik pada level pendidikan menengah dan tinggi tercermin dari beberapa penelitian yang telah dilakukan seperti oleh (Solihat, 2015); (Subekti et al., 2018); (Sari et al., 2019); (Roito et al., 2019); dan (Nurlaelah et al., 2020) dengan kesimpulan bahwa siswa menjadi subjek masih kurang menguasai keterampilan meneliti terutama pada aspek penggunaan metode penelitian, mengorganisir penelitian, menjawab hipotesis penelitian, dan publikasi penelitian. Melalui penelitian ini penulis mencoba mendeskripsikan aspek umum keterampilan meneliti berdasarkan hasil penilaian diri mahasiswa yang sedang menyelesaikan tugas akhir.

Hasil penelitian yang dilakukan Maknun (2020) menyimpulkan bahwa keterampilan meniliti pada mahasiswa Program Studi Pendidikan Biologi se-wilayah III Cirebon (yang meliputi pengambilan sampel di IAIN Syekh Nurjati Cirebon, Universitas Majalengka, dan Universitas Wiralodra) masih tergolong kurang (rendah) terutama pada aspek merancang dan melaksanakan penelitian, hasil penelitian (Aripin et al., 2021) menemukan bahwa aspek domain A (knowledge and intellectual abilities) merupakan domain keterampilan penelitian yang masih lemah dengan persentase penguasaan sebesar 35\%. Pengetahuan dan kemampuan intelektual mahasiswa dalam melakukan penelitian masih perlu ditingkatkan, hal ini mengidikasikan bahwa pembekalan teoritis keterampilan meneliti melalui kegiatan perkuliahan dirasakan masih kurang menurut mahasiswa.

Pengabdian kepada masyarakat ini bertujuan untuk memberikan pembekalan teoritis dan praktis bagi mahasiswa calon guru biologi dalam melakukan penelitian. PKM ini diharapkan akan mampu meningkatkan skills mahasiswa calon guru biologi dalam melakukan riset.

\section{Metode}

Metode yang digunakan pada PKM ini adalah workshop pembekalan keterampilan meneliti yang diharapkan dapat terjadi transfer of knowledge kepada peserta kegiatan. Metode untuk meningkatkan keterampilan meneliti pada calon guru biologi se-wilayah III Cirebon dilakukan melalui pembekalan pengetahuan, konsultasi dan bimbingan keterampilan meneliti serta praktik langsung menyusun proposal penelitian dan pembuatan artikel jurnal. Kegiatan PKM ini diharapkan akan mampu membekali keterampilan meneliti pada mahasiswa calon guru biologi di wilayah III Cirebon khususnya pada mahasiswa yang sedang menyusun tugas akhir skripsi atau kegiatan riset lainnya.

1. Prosedur Pelaksanaan

Prosedur pelaksanaan kegiatan pengabdian masyarakat yang dilaksanakan dimulai dari kegiatan pendahuluan dan survey lapangan untuk memetakan permasalah, merumuskan solusi terhadap permasalahan yang dihadapi mitra, perencanaan kegiatan, publikasi pelaksanaan kegiatan, pelaksanaan kegiatan, pemberian penugasan dan evaluasi. 


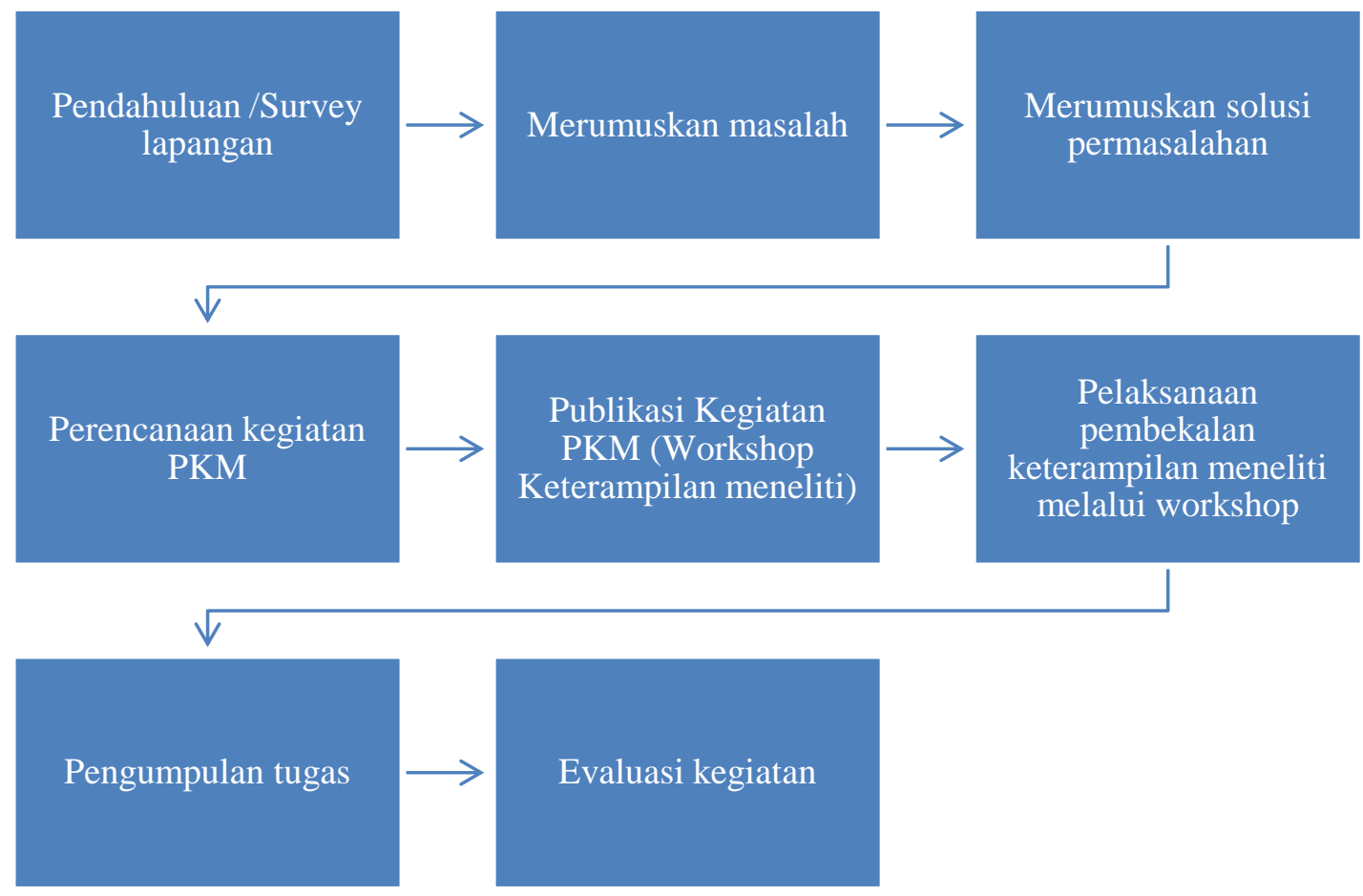

Gambar 1. Bagan Alur Kegiatan Workshop

2. Rancangan Kegiatan

Kegiatan ini dilaksanakan selama 1 bulan, yaitu bulan 8 Mei 2021 pelaksanaan kegiatan dan 29 Mei 2021 pengumpulan penugasan. Kegiatan ini menghadirkan praktisi internal dan eksternal Universitas Majalengka. Praktisi eksternal yang menjadi pemateri dalam workshop ini adalah Prof. Dr. Hj. Nuryani Rustaman, M.Pd. (Guru Besar Pendidikan Biologi Universitas Pendidikan Indonesia), dan Dindin Nasrudin, M.Pd. (Dosen UIN Sunan Gunung Djati Bandung) serta praktisi internal Dede Salim Nahdi, M.Pd. (P3M Universitas Majalengka).

\section{Hasil dan Pembahasan}

Kegiatan Pengabdian Kepada Masyarakat dengan tema "Pelatihan Keterampilan Meneliti untuk Calon Guru Biologi" ini dilaksanakan pada Sabtu, 08 Mei 2021 secara daring melalui aplikasi Zoom Meeting dengan melibatkan peserta yang berasal dari unsur mahasiswa, guru, dosen, widyaiswara dan praktisi pendidikan sebanyak 271 pendaftar dan sebanyak 112 peserta hadir secara online yang berasal dari beberapa Kota dan Provinsi di Indonesia seperti Bandung, Malang, Kudus, Yogyakarta, Aceh, Makasar, Banyuwangi, Lampur dan lain-lain. Kegiatan PKM ini menggunakan 6 tahapan proses, yaitu penyebaran informasi, pendaftaran peserta, pelaksanan kegiatan, penugasan praktik, dan evaluasi. Adapun hasil dari implementasi ke- 6 tahapan tersebut sebagai berikut.

1. Penyebaran Informasi

Kegiatan PKM ini dilaksanakan secara online sehingga strategi publikasi yang tepat akan menghasilkan jumlah peserta kegiatan sesuai dengan harapan. Poster kegiatan disebar melalui berbagai media seperti IG, FB dan WA grup untuk menjaring peserta kegiatan. Target utama peserta kegiatan ini adalah mahasiswa calon guru biologi kampus yang ada di wilayah III Cirebon serta mahasiswa calon guru biologi diberbagai kampus lain yang ada di Indonesia. Dari penyebaran informasi diperoleh 271 pendaftar dengan rata-rata memperoleh informasi dari poster IG (instagram) Pendidikan Biologi. 


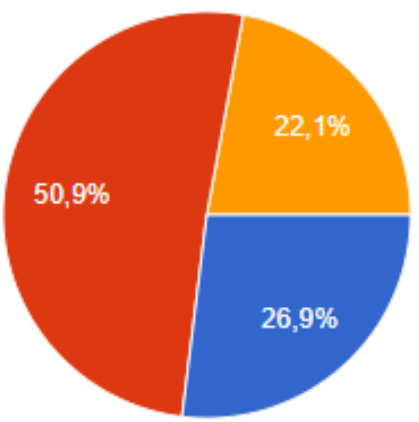

FB : Pendidikan Biologi Universitas

Majalengka

IG : Biology_education.unma

YT : Biologi UNMA

Gambar 2. Diagram Pie Distribusi Sebaran Informasi Peserta Kegiatan

IG memberikan kontribusi terbesar terhadap penyebaran informasi pelaksanaan PKM ini, sehingga strategi promosi kegiatan seperti ini kedepannya lebih efekif di promosikan melalui IG.

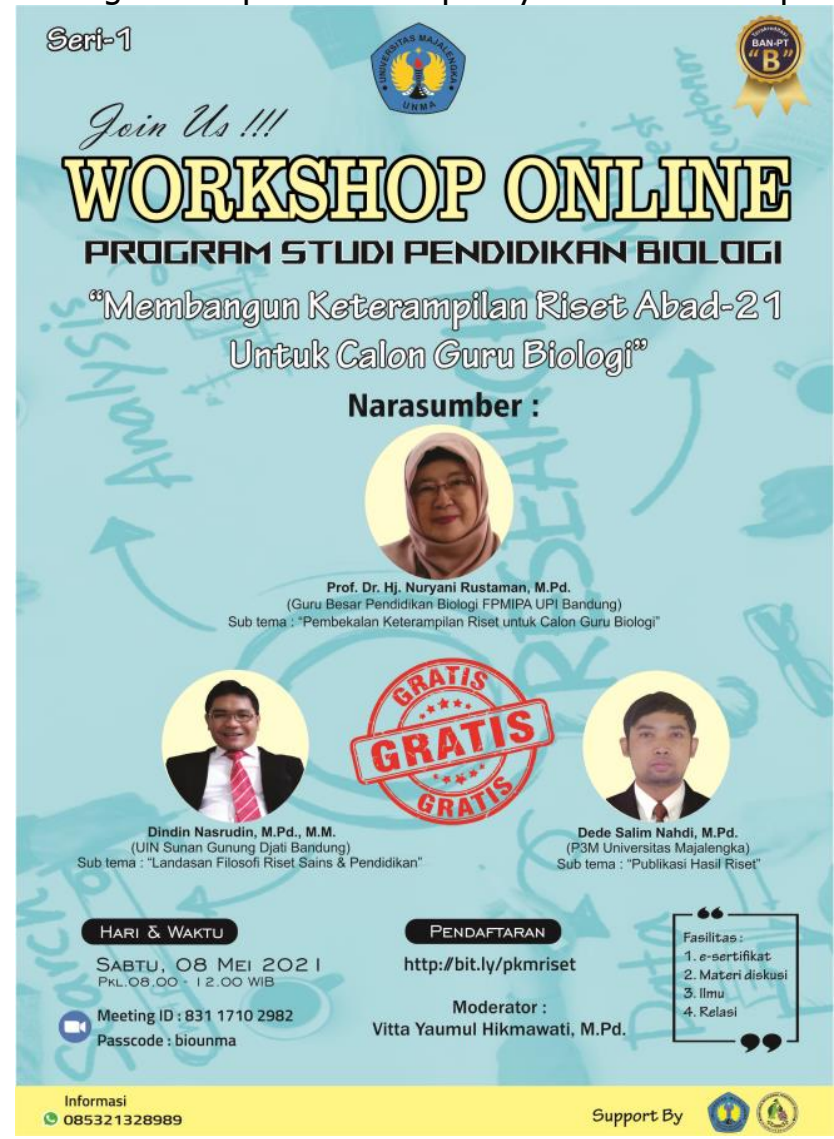

2. Pendaftaran peserta

Gambar 3. Poster Kegiatan PKM

Kegiatan PKM ini mentargetkan peserta yang berasal dari mahasiswa calon guru biologi kampus yang ada di wilayah III Cirebon serta mahasiswa calon guru biologi diberbagai kampus lain yang ada di Indonesia. Dari penyebaran informasi diperoleh 271 pendaftar dengan sebaran profesi sebagai berikut. 


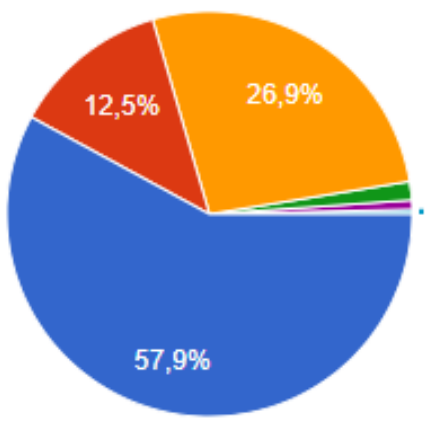

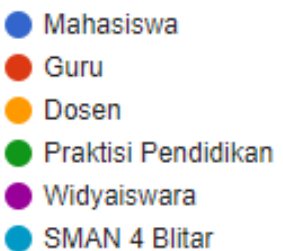

Gambar 4. Sebaran Peserta Kegiatan

Berdasarkan data yang diperoleh diketahui bahwa 57,9\% peserta adalah mahasiswa dan $26,9 \%$ dosen dan $12.5 \%$ guru, sisanya berasal dari berbagai profesi seperti praktisi pendidikan, dan widyaiswara. Sesuai dengan targetnya kegiatan ini diikuti sebagian besar oleh mahasiswa calon guru biologi.

3. Pelaksanaan kegiatan pembekalan materi

Dalam pelaksanaan kegiatan PKM ini dilakukan melalui presentasi, diskusi, drill \& practice antara pemateri dengan peserta dengan rancangan pelaksanaan kegiatan sebagai berikut.

Tabel 1. Jadwal Pelaksanaan Kegiatan

\begin{tabular}{|c|c|c|c|}
\hline No. & Jenis Kegiatan & Waktu & Narasumber \\
\hline 1. & $\begin{array}{l}\text { Pembekalan keterampilan } \\
\text { riset abad- } 21 \text { untuk calon } \\
\text { guru biologi }\end{array}$ & 08 Mei 2021 & $\begin{array}{l}\text { Prof. Dr. Hj. Nuryani Rustaman, M.Pd. } \\
\text { (Universitas Pendidikan Indonesia) }\end{array}$ \\
\hline 2. & $\begin{array}{l}\text { Pembekalan filosofi dasar } \\
\text { riset }\end{array}$ & 08 Mei 2021 & $\begin{array}{l}\text { Dindin Nasrudin, M.Pd. } \\
\text { (UIN Sunan Gunung Djati Bandung) }\end{array}$ \\
\hline 3. & $\begin{array}{l}\text { Pembekalan keterampilan } \\
\text { publikasi ilmiah }\end{array}$ & 08 Mei 2021 & $\begin{array}{l}\text { Dede Salim Nahdi, M.Pd. (Universitas } \\
\text { Majalengka) }\end{array}$ \\
\hline 4. & $\begin{array}{l}\text { Penugasan kegiatan } \\
\text { workshop }\end{array}$ & 09 Mei 2021 & Panitia \\
\hline 5. & Pengumpulan penugasan & 29 Mei 2021 & Panitia \\
\hline
\end{tabular}

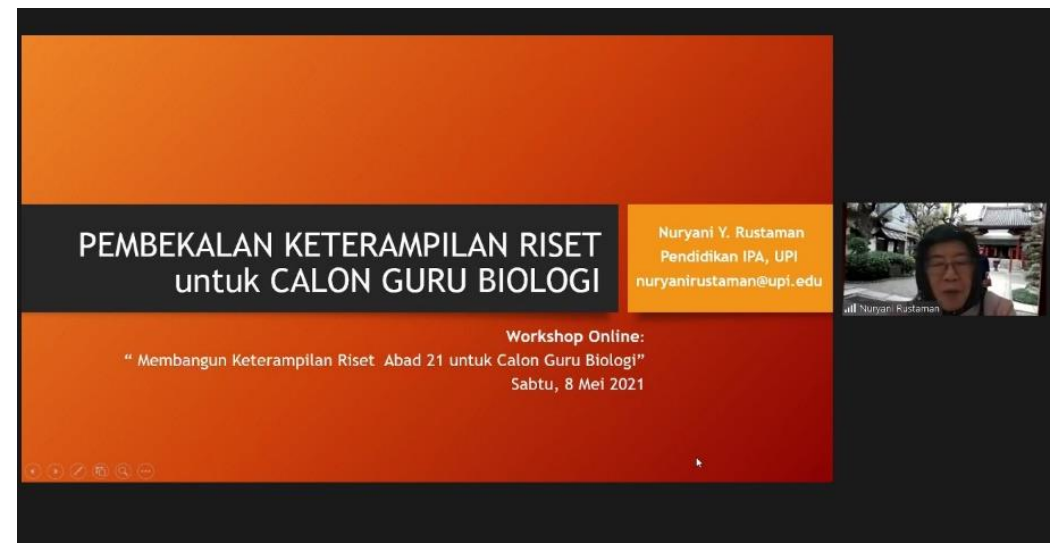



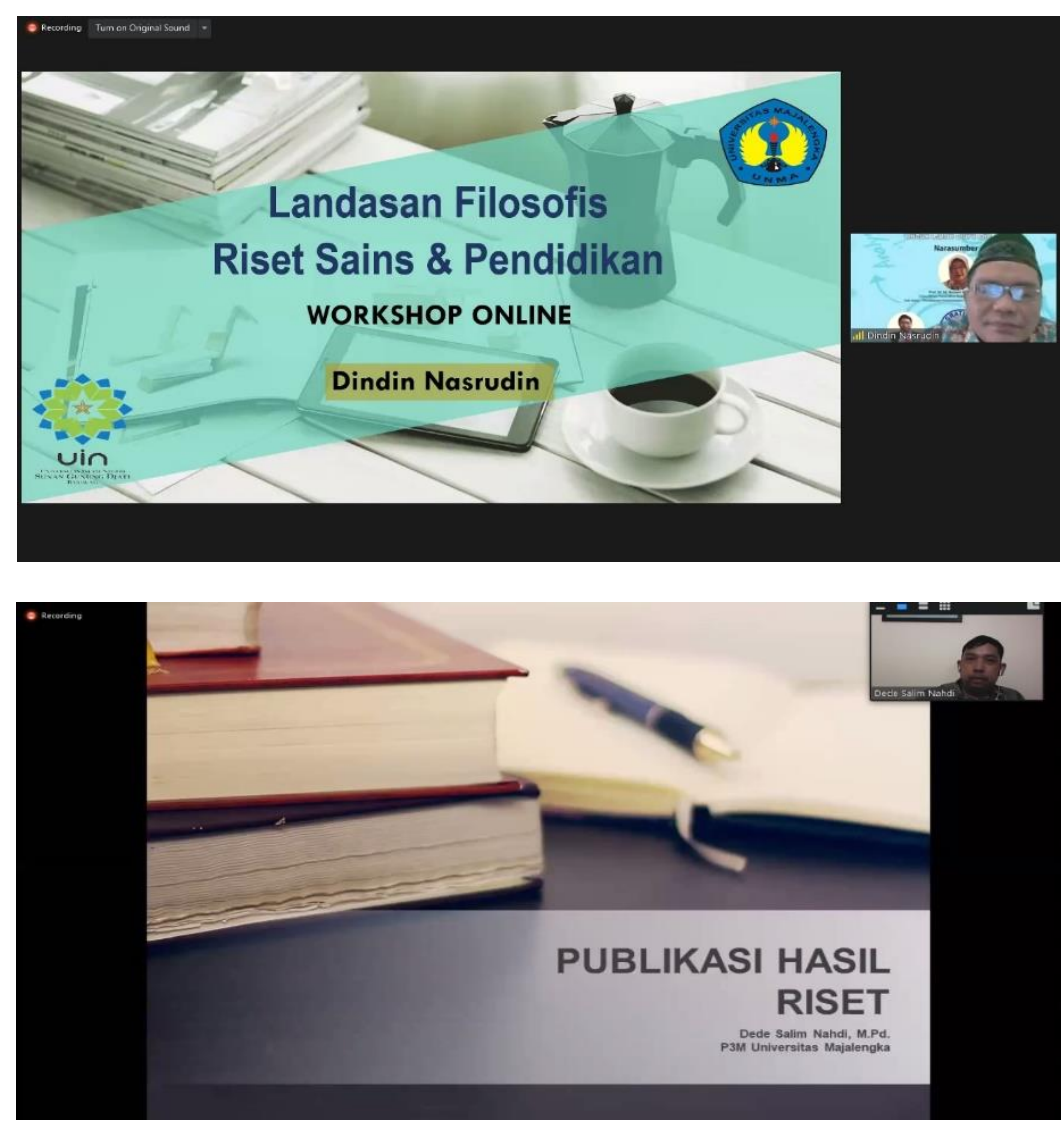

Gambar 4. Penyampaian Materi Workshop Keterampilan Meneliti

4. Pelaksanaan kegiatan praktik

Penugasan praktik di kumpulkan pada tanggal, 29 Mei 2021. Praktik penugasan keterampilan meneliti yang diberikan berupa praktik penugasan pembuatan proposal penelitian dan pembuatan artikel ilmiah.

\section{Penugasan praktik}

Kegiatan PKM ini memberikan penugasan praktik yang dikerjakan selama 3 minggu untuk seluruh peserta. Sebanyak 112 peserta yang berpartisipasi terdiri atas mahasiswa, guru, dosen dan masyarakat umum. Diketahui sebanyak 65 peserta adalah mahasiswa, sesuai tujuan dari PKM untuk memberikan bekal keterampilan meneliti pada mahasiswa calon guru biologi maka penugasan praktik yang dianalisis dalam PKM hanya peserta yang berasal dari kalangan mahasiswa saja. Berikut hasil analisis penugasan yang diberikan kepada peserta.

Tabel 2. Hasil Analisis Penugasan Peserta

\begin{tabular}{ccl}
\hline No. & Bentuk Penugasan & \multicolumn{1}{c}{ Hasil Analisis Tugas } \\
\hline 1. & Pembuatan proposal & Sebanyak 65 peserta mahasiswa calon guru biologi yang \\
& penelitian & berpartisipasi 19 diantaranya mengerjakan tugas pembuatan \\
& proposal riset yang telah diberikan. Berdasarkan hasil analisis \\
& terhadap tugas yang dibuat peserta terdapat beberapa \\
& proposal riset yang sudah baik secara penulisan maupun \\
& sistematika serta alur berpikir dari kegiatan riset yang akan \\
& dilakukan. Beberapa kekurangan dari proposal riset yang \\
& dibuat peserta antara lain masalah penelitian yang diangkat \\
& tidak jelas urgensinya, kerangka pemikiran yang diangkat \\
& dalam penelitian belum jelas, belum jelas metode yang akan
\end{tabular}


BERNAS:

Jurnal Pengabdian Kepada Masyarakat

\begin{tabular}{lll}
\hline No. & Bentuk Penugasan & \multicolumn{1}{c}{ Hasil Analisis Tugas } \\
\hline & & dipakai, tidak sinkron antara instrument yang akan digunakan \\
& dengan teknik analisis data yang akan dipakai. \\
2. Latihan pembuatan & Total 65 peserta mahasiswa calon guru biologi yang \\
artikel ilmiah hasil studi & berpartisipasi sebanyak 17 mengerjakan penugasan \\
literatur & pembuatan artikel ilmiah dari hasil studi literatur. Beberapa \\
& peserta sudah mampu membuat artikel dengan baik tetapi \\
& sebagian besar peserta masih belum memahami pembuatan \\
& artikel ilmiah. Beberapa kekurangan dari artikel yang dibuat \\
& oleh peserta antara lain: belum mengikuti template yang \\
& sudah diberikan, sistematika berpikir belum jelas, antara satu \\
& paragraph dengan yang lainnya tidak saling berhubungan, \\
& metode penelitian pada artikel masih tidak jelas, penulisan \\
& masih banyak yang belum sesuai PUEBI dan belum dapat \\
& membedakan kata depan atau imbuhan sehingga masih \\
& memerlukan penguatan dalam keterampilan penulisan dan \\
& penggunaan bahasa ilmiah, peserta juga belum bisa \\
& menggunakan aplikasi sitasi seperti Mendeley sehingga \\
& penulisan referensi masih dibuat secara manual.
\end{tabular}

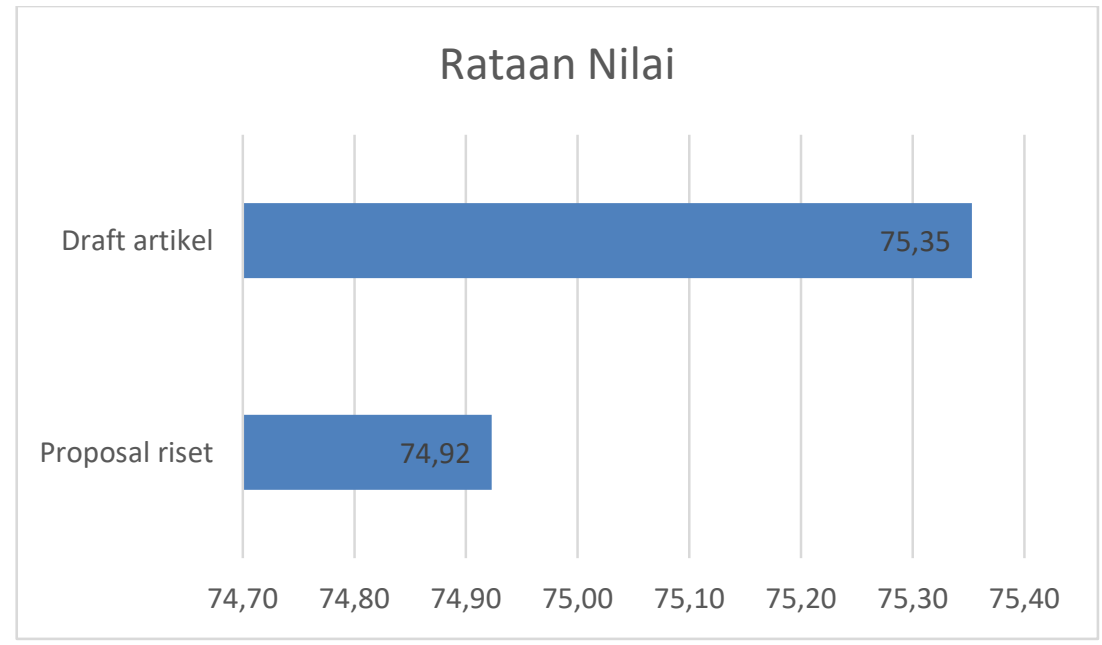

Gambar 5. Penilaian Penugasan Workshop

Gambar 5 menunjukkan hasil penilaian tugas yang diberikan pada kegiatan PKM. Tugas pembuatan proposal riset memperoleh skor rata-rata 74,92 (cukup baik) dan tugas pembuatan draft artikel dengan skor rata-rata 75,35 (cukup baik). Berdasarkan data skor penilaian terhadap tugas yang diberikan dalam workshop ini dapat diambil kesimpulan bahwa keterampilan riset mahasiswa masih memerlukan peningkatan dan PKM keterampilan meneliti harus lebih ditingkatkan pada taraf praktik dan aplikasi secara langsung agar peserta mampu meningkatkan keterampilan risetnya secara signifikan.

\section{Evaluasi}

Evaluasi pada kegiatan PKM menunjukkan bahwa seluruh peserta kegiatan menyatakan bahwa acara ini sangat bermanfaat dan meningkatkan pengetahuan dan keterampilan peserta terkait dengan keterampilan riset. Beberapa saran dari peserta terkait PKM ini antara lain:

1. Adanya pembekalan keterampilan riset dalam bidang biologi murni

2. Memberikan contoh secara langsung berbagai jenis keterampilan riset yang dapat dikembangkan peserta 
3. Praktik langsung kegiatan riset dalam bidang pendidikan dan sains murni

4. Pelaksanaan PKM ini sebaiknya dilaksanakan secara berkelanjutan

Dalam Peraturan Menteri Pendidikan dan Kebudayaan Republik Indonesia Nomor 65 Tahun 2013 tentang Standar Proses Pendidikan Dasar dan Menengah (2013) menyebutkan bahwa sasaran pembelajaran biologi mencakup pengembangan ranah keterampilan, pengetahuan, dan sikap. Keterampilan riset pada jenjang pendidikan dasar dan menengah sebagaimana yang tercantum dalam Permendikbud No. 22 Tahun 2016 tentang standar proses menyebutkan "untuk memperkuat pendekatan ilmiah (scientific), tematik terpadu (tematik antar matapelajaran), dan tematik (dalam suatu mata pelajaran) perlu diterapkan pembelajaran berbasis penyingkapan/penelitian (discovery/inquiry learning)". Berdasarkan penjelasan kedua Permen tersebut secara tersurat menyebutkan bahwa keterampilan riset (inquiry learning) merupakan salah satu bentuk pembelajaran yang direkomendasikan dalam pengembangan intelektual dan keterampilan pada siswa. Mengembangkan keterampilan meneliti pada siswa merupakan tanggung jawab guru yang dapat diimplementasikan melalui kegiatan pembelajaran yang dirancang.

Membekali keterampilan meneliti pada calon guru merupakan pondasi dasar untuk menghasilkan guru profesional yang berperan sebagai pengajar sekaligus peneliti sehingga dapat melakukan Continuous Professional Development (CPD) sehingga menghasilkan kualitas pembelajaran yang baik. Kegiatan PKM ini diharapkan memberikan input yang baik bagi pengembangan pengetahuan dan keterampilan mahasiswa calon guru biologi untuk melakukan riset.

Berdasarkan hasil analisis penugasan kegiatan PKM ini diketahui bahwa keterampilan membuat proposal riset dan draft artikel yang dikerjakan peserta memperoleh rata-rata penilaian dengan kategori cukup, artinya masih perlu peningkatan skill pada peserta agar lebih meningkatkan keterampilan dalam membuat proposal riset maupun publikasi ilmiah. Keterampilan pelaksanaan riset berdasakan hasil survey dalam kegiatan PKM ini merupakan keterampilan yang paling sulit atau kurang dikuasai oleh peserta, hasil ini tidak berbeda dengan yang dilakukan dalam penelitian (Solihat, 2015; Maknun et al., 2020) bahwa tahap pelaksanaan penelitian merupakan tahapan yang paling sulit/kurang dikuasai oleh mahasiswa oleh karena itu langkah strategis untuk PKM ini kedepannya adalah memberikan praktik langsung perencanaan, pelaksanaan, dan pelaporan kegiatan riset dengan menitik beratkan pada pembekalan dan implementasi pelaksaan riset. Research skills Development (RSD) yang dikembangkan oleh Willison \& O'Regan (2007) dapat digunakan sebagai framework dalam mengevaluasi perkembangan keterampilan riset pada mahasiswa calon guru biologi.

\section{Kesimpulan}

Hasil analisis terhadap respon peserta pada kegiatan PKM ini menyimpulkan bahwa peserta menyatakan bahwa kegiatan ini sangat bermanfaat dalam memberikan bekal dasar keterampilan meneliti. Hasil analisis terhadap penugasan yang diberikan menunjukkan bahwa tugas yang dikerjakan peserta tergolong cukup baik, artinya masih memerlukan pembekalan lebih lanjut terkait dengan teori dan khususnya praktik kegiatan meneliti pada peserta. Keterampilan dalam pelaksanaan (implementasi) penelitian menurut survey yang dilakukan pada PKM ini merupakan keterampilan yang kurang dikuasai oleh peserta. Kegiatan ini perlu dilakukan berkesimbungan dengan praktik langsung dalam bidang riset pendidikan juga dalam bidang sains terapan agar melatihkan mahasiswa calon guru menjadi pendidik juga peneliti yang handal.

\section{Daftar Pustaka}

Aripin, I., Hidayat, T., Rustaman, N. Y., \& Riandi, R. (2021). Prospective biology teachers' research skills. Journal of Physics: Conference Series, 1806(1). https://doi.org/10.1088/1742$6596 / 1806 / 1 / 012170$

Bandaranaike, S. (2018). Research Skill Development to Work Skill Development. Journal of University Teaching \& Learning Practice, 15(4). https://ro.uow.edu.au/jutlpAvailableat:https://ro.uow.edu.au/jutlp/vol15/iss4/7:https://ro.uo 
w.edu.au/jutlp/vol15/iss4/7

Kapon, S. (2016). Doing research in school: Physics inquiry in the zone of proximal development. Journal of Research in Science Teaching, 53(8), 1172-1197. https://doi.org/10.1002/tea.21325

Maknun, D., Gloria, R. Y., \& Muzakki, J. A. (2020). Keterampilan meneliti yang dimiliki mahasiswa prodi pendidikan biologi se-wilayah III Cirebon. Jurnal Inovasi Pendidikan IPA, 6(1), 39-47. https://doi.org/10.21831/jipi.v6i1.28251

Meerah, T. S. M., \& Arsad, N. M. (2010). Developing research skills at secondary school. Procedia Social and Behavioral Sciences, 9, 512-516. https://doi.org/10.1016/j.sbspro.2010.12.189

Nurlaelah, I., Widodo, A., Redjeki, S., \& Rahman, T. (2020). Student's research skills in middle school of Kuningan district. Journal of Physics: Conference Series, 1521(4). https://doi.org/10.1088/1742-6596/1521/4/042105

Richard Gott, P. M. (1987). Assessing Investigations at Ages 13 and 15. Assesment of Performance Unit.

Roito, E., Solihat, R., \& Wulan, A. R. (2019). Pencapaian Keterampilan Meneliti Abad Ke-21 Peserta Didik SMA pada Pembelajaran Ekosistem melalui Step-By-Step Model Experiment. Assimilation: Indonesian Journal of Biology Education, 2(1), 14-18.

Sari, D. P., Wulan, A. R., \& Solihat, R. (2019). Developing 21st century student research skills through assessment matrix and edmodo in biology project. Journal of Physics: Conference Series, 1157(2). https://doi.org/10.1088/1742-6596/1157/2/022093

Solihat, R. et al. (2015). Keterampilan Riset Mahasiswa Biologi dan Pendidikan Biologi; Analisis Berdasarkan Refleksi Personal. Metodik Didaktik, 9(2), 16-24.

Subekti, H., Yuhanna, W. L., \& Susilo, H. (2018). Representation of Mutual Terms and Research Skills Towards Grade Point Average: Exploration Study. Florea, 5(1), 1-10.

Voogt, J., \& Roblin, N. P. (2012). A comparative analysis of international frameworks for $21 \mathrm{st}$ century competences: Implications for national curriculum policies. Journal of Curriculum Studies, 44(3), 299-321. https://doi.org/10.1080/00220272.2012.668938

Willison, J., \& O'Regan, K. (2007). Commonly known, commonly not known, totally unknown: a framework for students becoming researchers. Higher Education Research and Development, 26(4), 393-409. https://doi.org/10.1080/07294360701658609 